\title{
Wear Behaviour of Eutectic Al-Si Alloy-Graphite Composites Fabricated by Combined Modified Two-Stage Stir Casting and Squeeze Casting Methods
}

\author{
P. Shanmughasundaram ${ }^{1}$ and R. Subramanian ${ }^{2}$ \\ ${ }^{1}$ Department of Mechanical Engineering, Karpagam College of Engineering, Coimbatore 641032, India \\ ${ }^{2}$ Department of Metallurgical Engineering, PSG College of Technology, Coimbatore 641004, India \\ Correspondence should be addressed to P. Shanmughasundaram; sunramlec@rediffmail.com
}

Received 19 May 2013; Accepted 22 July 2013

Academic Editor: Pavel Lejcek

Copyright (C) 2013 P. Shanmughasundaram and R. Subramanian. This is an open access article distributed under the Creative Commons Attribution License, which permits unrestricted use, distribution, and reproduction in any medium, provided the original work is properly cited.

\begin{abstract}
Dry sliding wear behaviour of eutectic Al-Si alloy-graphite composites was investigated employing a pin-on-disc wear test rig. Results revealed that the wear and friction coefficients decreased linearly with increasing weight percentage of graphite particles. Wear resistance of the composite increased considerably with increasing sliding velocity at constant load. In contrast, the friction coefficient of Al-7.5 wt.\% Gr composite increased when the sliding velocity was increased from $1 \mathrm{~m} / \mathrm{s}$ to $2 \mathrm{~m} / \mathrm{s}$ at $49 \mathrm{~N}$. Worn-out surfaces of wear specimens after the test were examined by scanning electron microscopy to study the morphology of worn surfaces. EDS analysis was carried out to investigate the influence of mechanically mixed layer (MML) which comprises oxides and iron, and this acted as an effective tribolayer in enhancing the wear resistance at higher sliding velocity.
\end{abstract}

\section{Introduction}

Metal matrix composites are being employed in industrial applications since they have high specific strength, stiffness, and better wear properties. Wear is the removal of material from one or both of the two solid surfaces in a solidstate contact. Solid lubricants are used for applications in which any sliding contact occurs to reduce the friction. Solid lubricant provides protection from damage during relative movement between the sliding elements to reduce the friction and wear [1]. Aluminium alloy-graphite composites have better tribological characteristics, which is one of the most desirable features in automotive engine pistons, bearings, and bushings. The addition of graphite particles to the aluminium alloy matrices makes the alloy self-lubricating since they act as solid lubricants. Eutectic Al-Si alloys have high strength to weight ratio and low coefficient of thermal expansion, and this makes them attractive candidate materials in many tribological applications. Lin et al. [2] analyzed the tribological behaviour of $6061 \mathrm{Al}$ alloy matrix composite and reported that an increase in graphite content increases the wear resistance of composites. Ames and Alpas [3] reported that the Al-Gr composites had higher wear resistance than the Al$\mathrm{SiC}$ composites. Das et al. [4] analyzed the wear rate of Al$\mathrm{Si}$ alloy graphite composites and reported that the graphite particles and silicon phase were found to have an influence on the tribological behavior of the composites. Liu et al. [5] observed that Al alloy-graphite composites offer lower friction coefficient and wear rate. Leng et al. [6] reported that the addition of graphite particles increase the wear resistance of the $\mathrm{Al}$ alloy-SiC reinforced composites. Gibson et al. [7] studied the influence of graphite particles on the wear characteristics of cast Al-Si alloys produced by compo casting followed by squeeze casting. They reported that an increase in graphite content reduces the coefficient of friction and temperature rise in the wear pin. Pai et al. [8] reported that the high wear resistance is attributed to the presence of graphite particles in the matrix which act as a solid lubricant. Krishnan et al. [9] emphasized that the superior performance of the aluminium alloy graphite bearings is attributed to 
the formation of a tribo-induced graphite-rich layer on the bearing surface.

In order to explore the possibilities of using $\mathrm{Al} /$ graphite composites as structural materials, mechanical properties need to be enhanced by controlling the nature of the distribution of the graphite particles and the interface that exists between the graphite and the matrix [10]. Achieving a uniform distribution of graphite particles in the $\mathrm{Al}$ alloy is a challenge in the stir casting process, which directly affects the mechanical and tribological properties of composites. Inherent difficulties associated with stir casting method are segregation, poor wettability of the graphite particles by liquid $\mathrm{Al}$ alloy, and higher porosity which occurs as a result of gases entrapped during fabrication. A modified two-stage stir casting method can be employed to enhance the uniform distribution of the graphite particles in the $\mathrm{Al}$ alloy matrix. In the first stage, stirring takes place when the composite slurry is in a semisolid state. Then the slurry is reheated to liquidus temperature of $\mathrm{Al}$ and the second stage of stirring starts in the liquid state until the slurry is poured in a mould. The emphasis was to prevent the accumulation of graphite particles and uneven distribution of particles in the melt. Radial impeller with $0.7 \mathrm{I}_{\mathrm{OD}} / \mathrm{C}_{\mathrm{ID}}$ ratio (Impeller outer dia to Crucible inner dia) is used to achieve the sufficient turbulence in the margin area and prevent deposition of the graphite particles on the wall surface of the crucible. During stirring process, the impeller is continuously moved vertically within the slurry at a rate of $2 \mathrm{~mm} / \mathrm{s}$ by means of stirrer position control unit [11]. On the other hand, squeeze casting method in which composite melt is solidified without turbulence or gas entrapment in the mould cavity under high pressure is employed to produce dense composites.

In this study, combination of both the modified two-stage stir casting and squeeze casting methods was employed to fabricate the high dense Al-graphite composites. Dry sliding wear and frictional behaviours of Al-Si alloy-Gr composites with different weight fractions of graphite particles were studied under two different sliding velocities at constant applied load. Scanning electronic microscopy (SEM) was employed to study the microstructure of composites and the morphology of the worn surfaces of the composites. Energy dispersive X-ray spectroscopy (EDS) was used to characterize the mechanically mixed layer (MML) which is formed on the worn surface during sliding wear and to elucidate its influences on the wear behaviour of composites.

\section{Experimental}

2.1. Specimen Preparation. In this study, eutectic Al-Si alloy was used as the matrix material, and graphite particles (50120 microns) were used as the solid lubricant. Composition of Al-Si alloy is presented in Table 1. Stir casting and squeeze casting setups are shown in Figures 1 and 2.

Combination of both the modified two-stage stir casting [12] and squeeze casting methods was employed to fabricate the composites. A blue star universal testing machine (UTE40) which is shown in Figure 2 was slightly customized to apply pressure on the molten composite in the mould cavity.
TABLE 1: Composition of Al-Si alloy.

\begin{tabular}{lcccc}
\hline Element & $\mathrm{Si}$ & $\mathrm{Fe}$ & $\mathrm{Mg}$ & $\mathrm{Al}$ \\
\hline wt.\% & 12.6 & 0.02 & 0.20 & $\mathrm{Bal}$ \\
\hline
\end{tabular}

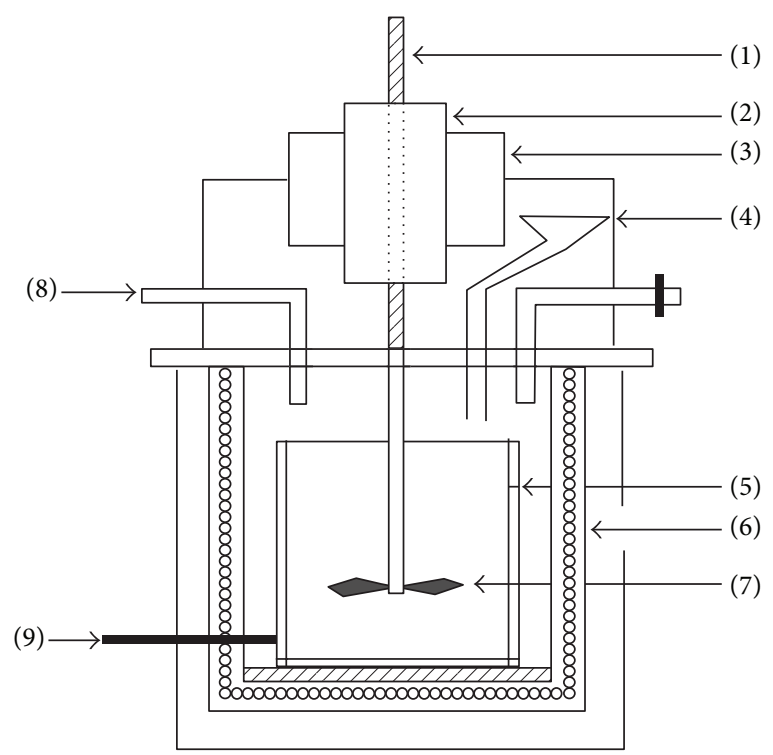

FIGURE 1: Schematic of modified two-stage stir casting setup. (1) Stirrer spindle, (2) sliding mechanism with impeller position control unit, (3) electric motor, (4) sprue, (5) crucible, (6) electric furnace, (7) impeller, (8) argon gas inlet, and (9) thermocouple.

In this method, $\mathrm{Al}$ alloy was charged into the graphite crucible and the furnace temperature was raised up to liquidus temperature of $\mathrm{Al}$ in order to melt the $\mathrm{Al}$ scraps completely. During stirring, preheated graphite particles were added into the crucible at the side of the vortex. $1.5 \mathrm{wt} . \% \mathrm{Mg}$ was added to the melt to promote the wetting action between $\mathrm{Al}$ matrix and graphite particles. The melt temperature was brought down to $575^{\circ} \mathrm{C}$ to achieve the semisolid state. Stirring was done for 3 minutes in the semisolid state. Argon gas was continuously blown at the rate of $2 \mathrm{cc} / \mathrm{min}$ into the furnace during the process to minimize the oxidation problems. The composite slurry was again reheated to the liquidus temperature of $660^{\circ} \mathrm{C}$ and stirred at $300 \mathrm{rpm}$ for 3 minutes. Finally, composite slurry was poured into the preheated mould cavity which is maintained at $350^{\circ} \mathrm{C}$. $50 \mathrm{MPa}$ squeeze pressure was applied on the melt for 40 seconds through the preheated punch till solidification was completed. Punch was withdrawn and specimen was removed from the mould assembly.

2.2. Microstructural Study. Scanning electron microscopy was employed to study the distribution of graphite particles in the Al matrix and bonding quality between the particulates and matrix.

2.3. Hardness. Hardness test was performed on $\mathrm{Al}$ alloy and composite specimens using Brinell hardness testing rig with $10 \mathrm{~mm}$ diameter at a load of $4.9 \mathrm{kN}$ (500 Kgf). The loading 


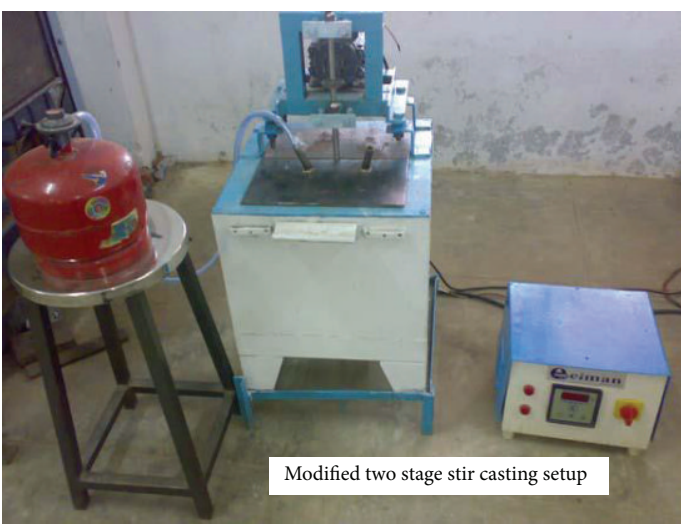

(a)

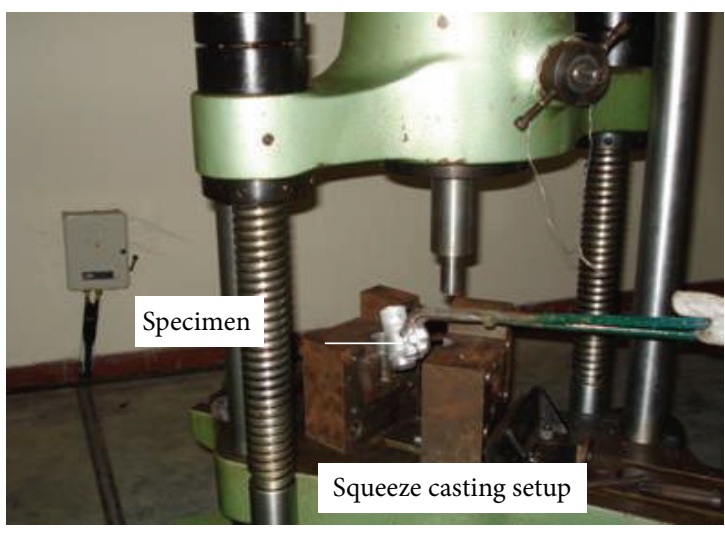

(b)

FIGURE 2: Modified two-stage stir casting (a) squeeze casting (b) setups.

time was 30 seconds. Three readings were taken on each specimen to eliminate possibility of segregation, and mean value was considered.

2.4. Dry Sliding Wear Test. The wear tests were carried under constant normal load of $49 \mathrm{~N}$ (5 kgf) at sliding velocities of $1 \mathrm{~m} / \mathrm{s}$ and $2 \mathrm{~m} / \mathrm{s}$ by employing a pin-on-disc wear testing rig (DUCOM, TR-20LE) with a data acquisition system which is shown in Figure 3.

The main parts of the apparatus are variable velocity electric motor with a carbon disc attached to it and a lever arm on which weight is added. The wear loss of sample pins was measured in terms of height loss in microns with accuracy $1.0 \mu \mathrm{m}$ and recorded by the linear variable differential transducer (LVDT) provided in the wear testing apparatus. Track diameter of $100 \mathrm{~mm}$ was selected for the analysis. The rotating disc was made of EN 31 steel having hardness of 62 HRC. Pin specimens with a square size of $6 \mathrm{~mm}$ and $30 \mathrm{~mm}$ length were prepared. Prior to wear testing, specimens were polished with abrasive paper of grade 600 and followed by grade 1000 . Wear tests were carried out at $30^{\circ} \mathrm{C}$ room temperature for 15 minutes. However, in this study, wear loss readings were taken at the end of 800 second (13.3 minutes). Minimum of 3 samples were tested for each condition. SEM examination was carried out on the wear surfaces of specimens in order to understand the mechanisms of wear under the various test conditions.

\section{Results and Discussion}

Figure 4 shows the microstructure of the Al-7.5 wt.\% Gr composite fabricated through the two-stage stir casting method followed by squeeze casting method. It can be seen that the graphite particles are distributed uniformly and well bonded with the aluminum matrix. The interface between the $\mathrm{Al}$ matrix and graphite particles is clean and ensures a strong interfacial bonding. No agglomeration of the graphite particles or porosity was observed in the composite.

Figure 5 shows that the hardness of Al-Gr composites gradually decreases as graphite content increases. It can be

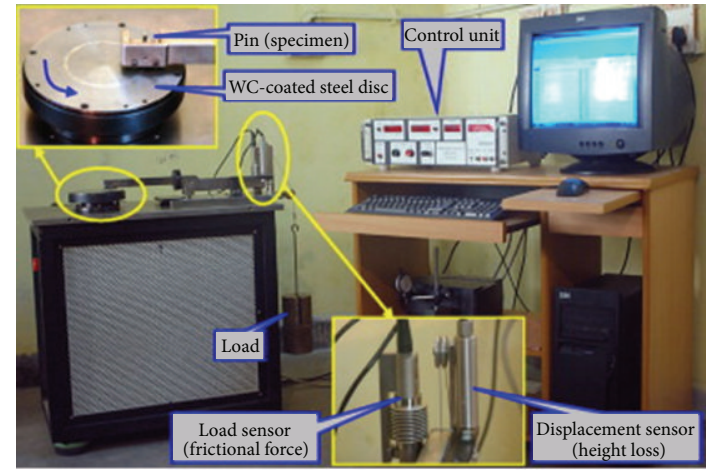

FIGURE 3: Pin-on-disc wear testing rig.

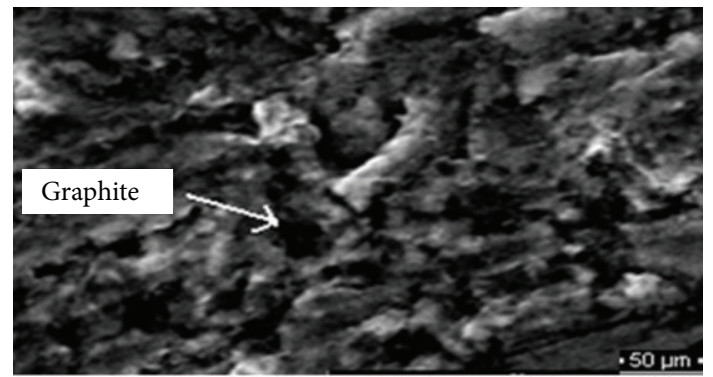

FIGURE 4: SEM micrograph of the Al-7.5 wt.\% Gr composite fabricated through two-stage stir casting followed by squeeze casting method.

explained by the fact that the graphite has lower hardness than the Al-Si alloy. The hardness of the Al-7.5 wt.\% Gr was about 33\% lower than that of the hardness of the Al alloy. A similar observation was made by the Hassan et al. [13].

A comparative study on the hardness of composites fabricated by the two-stage stir casting method and the combined two-stage stir casting and squeeze casting methods was carried out. It can be observed from the Figure 5 that the hardness of the Al-7.5 wt.\% Gr composite specimens fabricated through combined method showed 31\% higher 


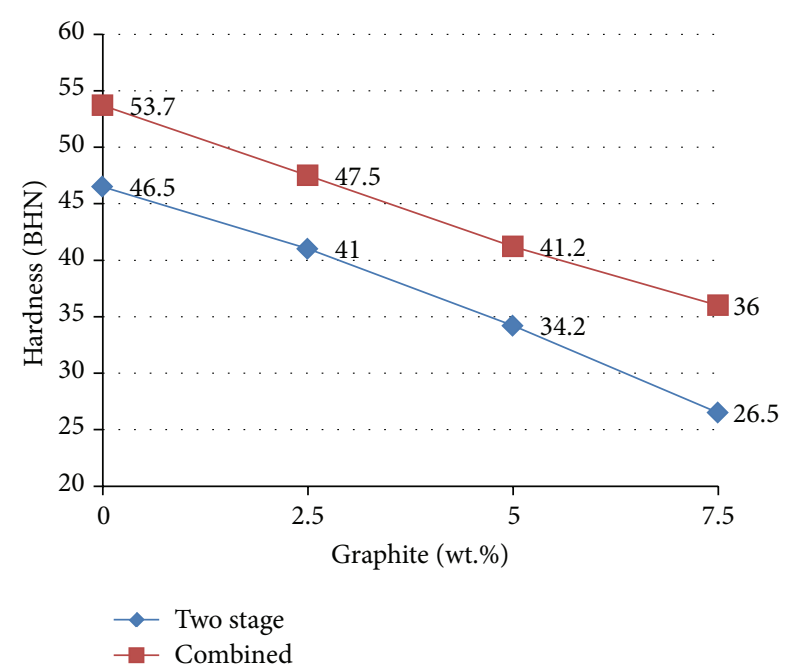

Figure 5: Hardness of specimens.

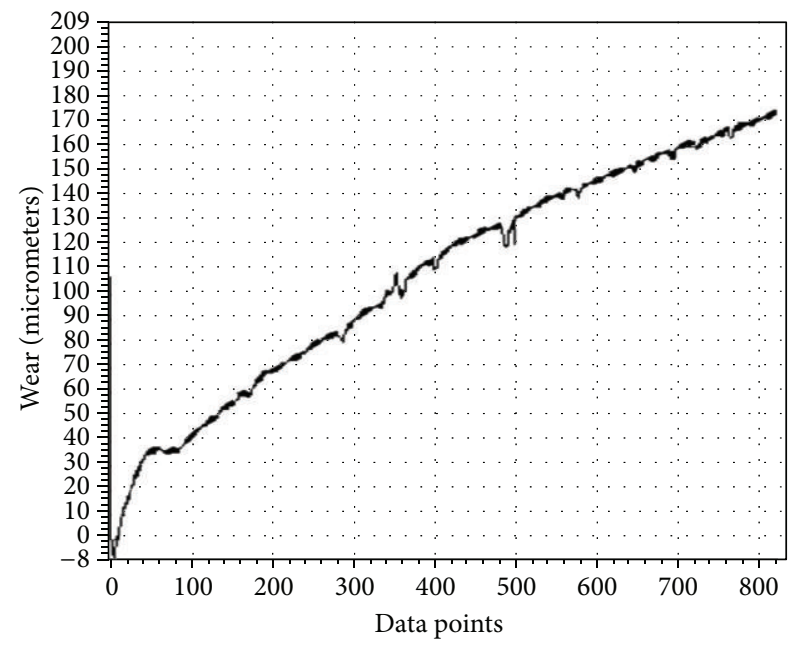

FIgURE 6: Typical curve of wear of Al-7.5 wt.\% Gr composite against steel as a function of sliding time at $1 \mathrm{~m} / \mathrm{s}$ and $49 \mathrm{~N}$.

value than those obtained in two-stage stir cast specimens. This can be attributed to the fact that the graphite particles are uniformly distributed in the Al matrix with absence of porosity. This was consequently reflected in the microstructure of the Al-7.5 wt.\% Gr composite.

Typical curves of wear loss of Al-7.5 wt.\% Gr composite against sliding time as a function of sliding velocities of $1 \mathrm{~m} / \mathrm{s}$ and $2 \mathrm{~m} / \mathrm{s}$ at constant applied load of $49 \mathrm{~N}$ are presented in Figures 6 and 7, respectively. It can be observed that the wear of the Al-Gr composites material increases as the sliding time is increased. This is because the instability of the tribolayer which is formed during sliding on the worn surface, at longer sliding distances.

It can be observed from Figure 8 that the wear resistance of the Al-graphite composites increases with the increasing graphite content. This can be attributed to the fact that the graphite particles act as solid lubricant and enhance the wear resistance. The lowest wear loss was obtained for composite

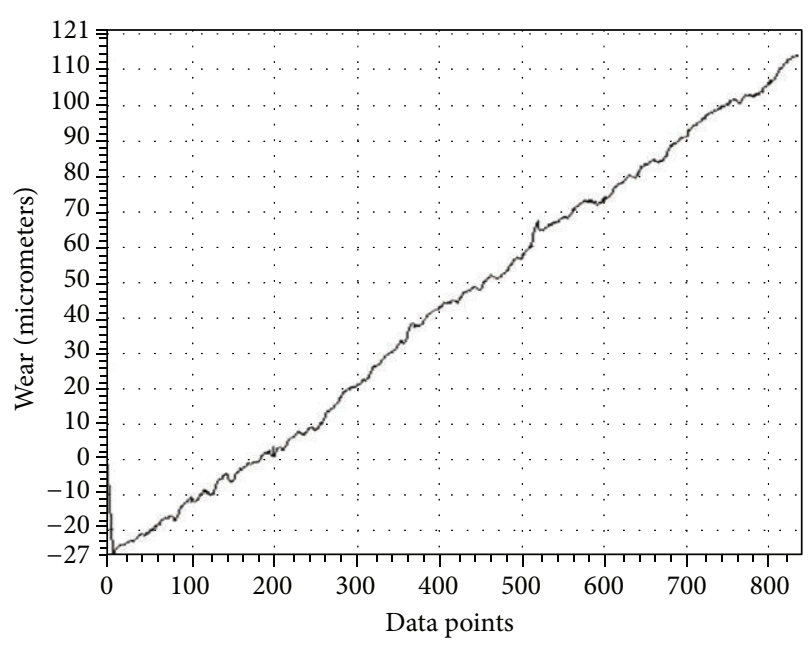

FIgURE 7: Typical curve of wear of Al-7.5 wt.\% Gr composite against steel as a function of sliding time at $2 \mathrm{~m} / \mathrm{s}$ and applied load $49 \mathrm{~N}$.

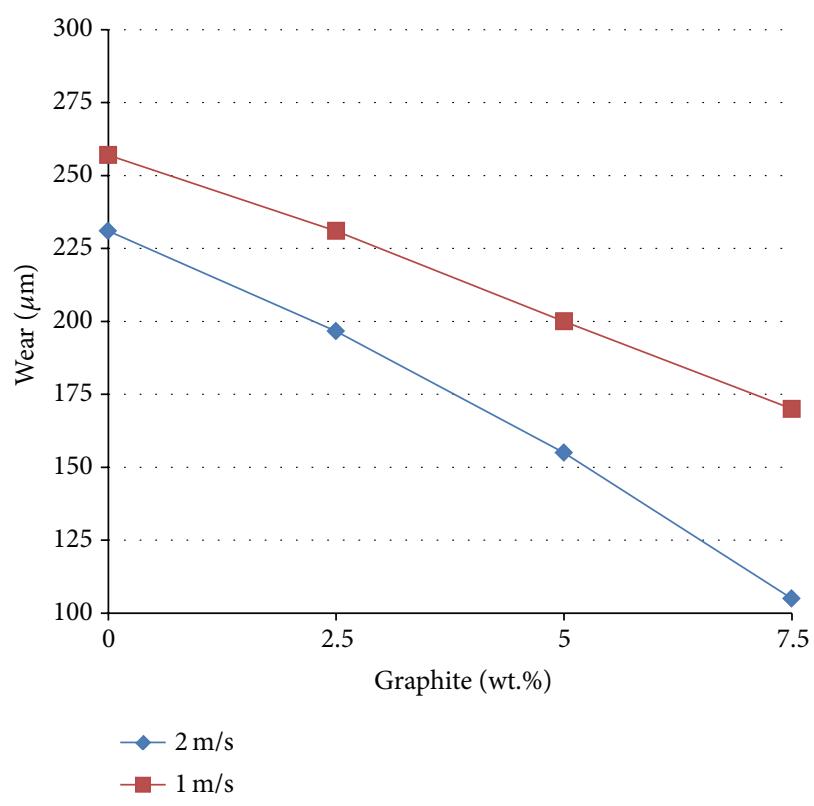

FIGURE 8: Variation of wear as a function of graphite content and sliding velocities of $1 \mathrm{~m} / \mathrm{s}$ and $2 \mathrm{~m} / \mathrm{s}$ at constant normal load of $49 \mathrm{~N}$.

with 7.5 wt.\% graphite content. It exhibits wear resistance approximately 2.2 times higher than that of Al alloy at $2 \mathrm{~m} / \mathrm{s}$ sliding velocity and $49 \mathrm{~N}$ load.

This increase in wear resistance can also be attributed to a better interfacial bonding between $\mathrm{Al}$ and graphite particles which help in preventing the damages caused due to sliding action. Generally, higher sliding velocity generates higher frictional heat which accelerates the oxidation process, and tribolayer is much easier to form.

It can also be observed from Figure 8 that wear loss of the Al-graphite composites tended to decrease when the sliding velocity was increased from $1 \mathrm{~m} / \mathrm{s}$ to $2 \mathrm{~m} / \mathrm{s}$ at load of $49 \mathrm{~N}$. Wear resistance increases when increasing the sliding velocity at constant load regardless of weight percentage of graphite 


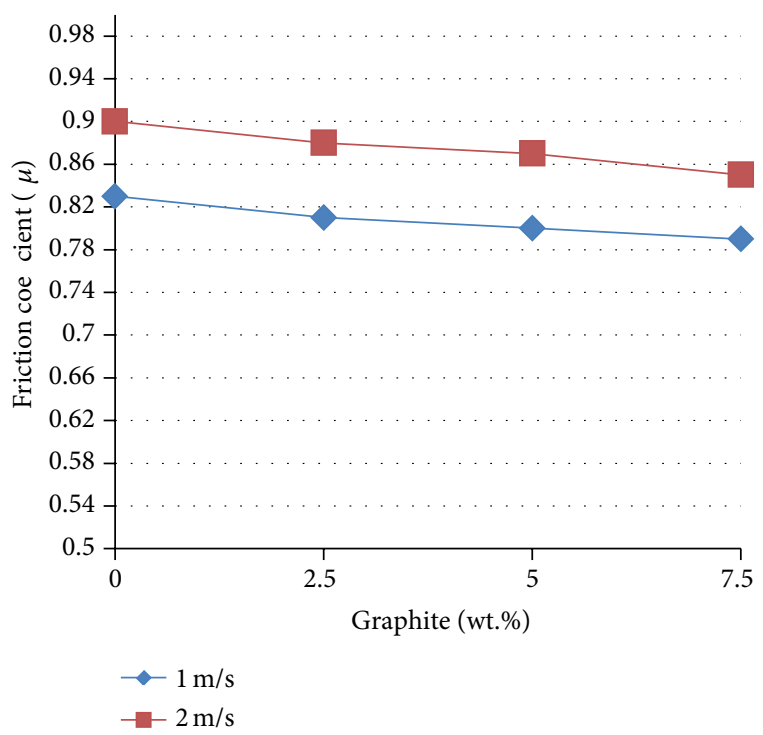

FIGURE 9: Variation of friction coefficient as a function of graphite content and sliding velocities of $1 \mathrm{~m} / \mathrm{s}$ and $2 \mathrm{~m} / \mathrm{s}$ at constant normal load of $49 \mathrm{~N}$.

particles of $\mathrm{Al}-\mathrm{Gr}$ composites. It is evident from Figure 8 that the higher wear is obtained at a sliding velocity of $1 \mathrm{~m} / \mathrm{s}$, whereas low wear is obtained at a sliding velocity of $2 \mathrm{~m} / \mathrm{s}$ at the constant applied load of $49 \mathrm{~N}$. This can be attributed to the fact that the higher sliding velocity increases the wear resistance through the formation of stable mechanically mixed layer (MML) on the surface of the composite during wear process. Similar observation was noticed by Lin et al. on Al-Gr (0-6 wt.\%) composites [2].

Figure 9 illustrates the friction coefficient curve of matrix and composite at sliding velocities of $1 \mathrm{~m} / \mathrm{s}$ and $2 \mathrm{~m} / \mathrm{s}$ under a normal load of $49 \mathrm{~N}$. The friction coefficient begins at 0.83 for the Al-Si alloy and decreases with increased graphite content reaching to a final value of about 0.79 for Al-7.5 wt.\% composite which is subjected to $1 \mathrm{~m} / \mathrm{s}$ and $49 \mathrm{~N}$. It infers that the friction coefficient decreases gradually with increasing graphite content regardless of sliding velocity. As the weight percentage of graphite increases, more graphite particles which are supposed to be exposed on the worn surface, form a thin layer which reduces the coefficient of friction. On the other hand, friction coefficient of Al-7.5 wt.\% Gr composite increases from 0.79 to 0.85 as the sliding velocity increases from $1 \mathrm{~m} / \mathrm{s}$ to $2 \mathrm{~m} / \mathrm{s}$ at $49 \mathrm{~N}$. It was found that friction coefficient of the Al-7.5 wt.\% Gr composites increased by $8 \%$. This could be the reason of the more adhesion between the asperities of composite pin material and the counter steel disc materials at higher sliding velocities.

\section{Morphology of Worn Surfaces}

Figure 10 shows the wear track morphology of $\mathrm{Al}$ alloy. The worn surface of $\mathrm{Al}$ is characterized by the fairly long and ploughing grooves, and the material has been removed on the surface in the form of thin sheets through delamination. Since the $\mathrm{Al}$ alloy matrix is much softer than the carbon steel disc,

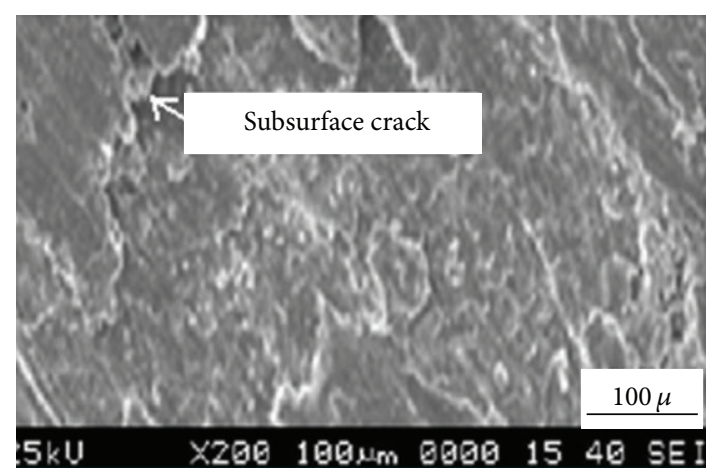

FIGURE 10: SEM micrograph of the worn surface of the Al alloy at a normal load of $49 \mathrm{~N}$ with $2 \mathrm{~m} / \mathrm{s}$ sliding velocity.

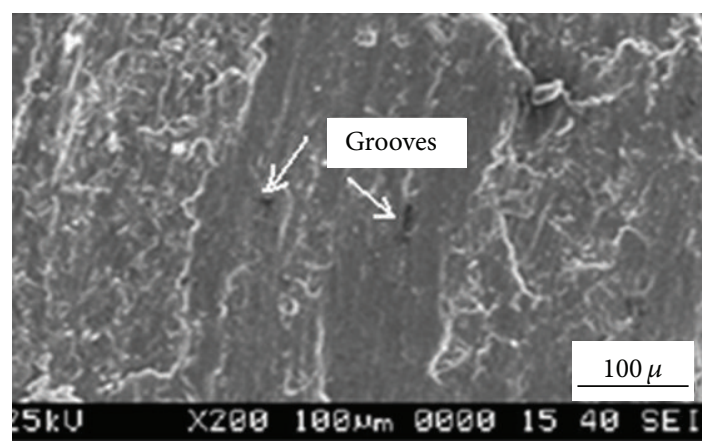

FIGURE 11: SEM micrograph of the worn surface of the Al-2.5 wt.\% $\mathrm{Gr}$ composite at a normal load of $49 \mathrm{~N}$ with $2 \mathrm{~m} / \mathrm{s}$ sliding velocity.

the asperities on steel counter face penetrate to larger depth into the surface and cut severely, resulting in a greater amount of material loss.

It is also observed that plastic deformation at the edges of the groove is large and develops subsurface cracking which leads to larger material removal.

It can be seen from the worn surface of Al-2.5 wt.\% Gr composite (Figure 11) that the extent of material removal is not as much as in the case of $\mathrm{Al}$ alloy. In addition, the wear grooves were smaller along the sliding direction due to the incorporation of graphite particles. Relatively slight plastic deformation was noticed at the edge of the grooves compared to worn surface of $\mathrm{Al}$ alloy. Since the graphite particles tend to prevent the $\mathrm{Al}$ matrix from direct contact with the counterpart, they enhance the resistance to wear. This observation supports the lower wear loss of the composites compared to the $\mathrm{Al}$ alloy.

Worn surface of composite when it is subjected to $40 \mathrm{~N}$ load at $2 \mathrm{~m} / \mathrm{s}$ sliding velocity is shown in Figure 13. The sliding marks obtained at $2 \mathrm{~m} / \mathrm{s}$ velocity become relatively smooth compared with that at low velocity $(1 \mathrm{~m} / \mathrm{s})$ (Figure 12) when viewed at the same magnification. It can be noted that when the sliding velocity increases from $1 \mathrm{~m} / \mathrm{s}$ to $2 \mathrm{~m} / \mathrm{s}$, graphite particles spread on the worn surface and act as lubricating film which increases the wear resistance. Moreover, at higher sliding velocity graphite particles and the counter face $(\mathrm{Fe})$ reacts with oxygen in the air and forms iron oxide due to 


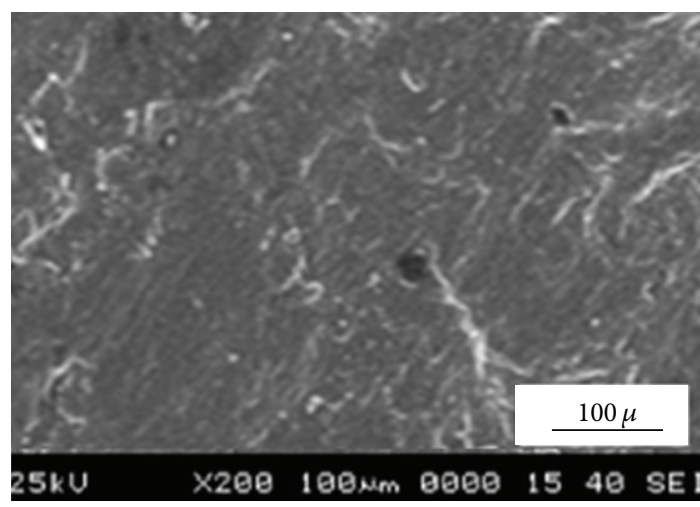

FIGURE 12: SEM micrograph of the worn surface of the Al-7.5 wt.\% Gr composite at a normal load of $49 \mathrm{~N}$ with $1 \mathrm{~m} / \mathrm{s}$ sliding velocity.

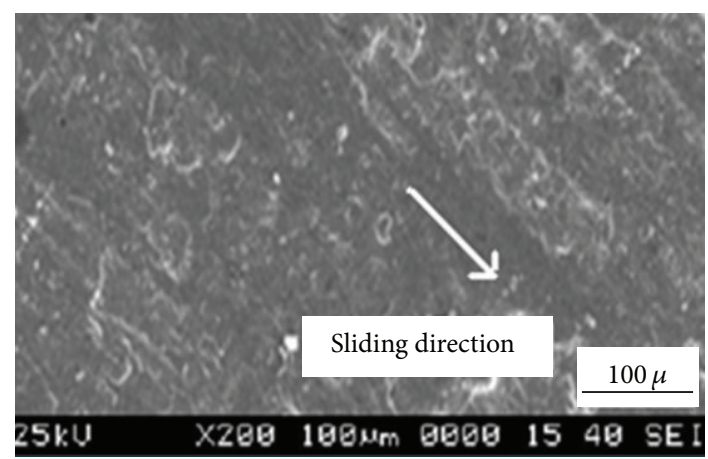

FIGURE 13: SEM micrograph of the worn surface of the Al-7.5 wt.\% $\mathrm{Gr}$ composite at a normal load of $49 \mathrm{~N}$ with $2 \mathrm{~m} / \mathrm{s}$ sliding velocity.

higher frictional heating. The oxides and graphite particles form a mechanically mixed layer (MML) and appear on the worn surface of the composite pin.

EDS analysis was performed employing JEOL 6360-ZAF method (standard less quantitative analysis) to determine the elements on the worn surface of composite.

Surface layer of Al-7.5 wt.\% graphite composite before the wear testing is presented in Figure 14. It shows that this film primarily consists of $\mathrm{Al}, \mathrm{Si}, \mathrm{Mg}$, and $\mathrm{C}$ which are present in $\mathrm{Al}$ alloy-Gr composite. High magnification view of the surface layer (the area of rectangle) of Al-7.5 wt.\% graphite composite at normal load of $49 \mathrm{~N}$ with $2 \mathrm{~m} / \mathrm{s}$ sliding velocity is presented in Figure 15. EDS test reveals that this film is primarily comprised of $\mathrm{Al}, \mathrm{Si}, \mathrm{C}, \mathrm{Fe}$, and $\mathrm{O}$.

It can be observed from Figure 16 that the elements such as negligible amount of $\mathrm{Fe}$ and $\mathrm{O}$ were detected on the worn surface of Al-Si alloy. It is obvious that no MML was evident on the worn surface of the $\mathrm{Al}$ alloy. MML formation rate depends on the wear rate and type of wear mechanism. This can be attributed to the fact that load causes severe plastic deformation and consequent removal of $\mathrm{Al}$ which leads higher delamination wear that retards the formation of MML. Rosenberger et al. [14] reported that both MML formation rate and MML fracture rate should be necessarily equal to attain the constant MML thickness which ensures the steady state wear condition.

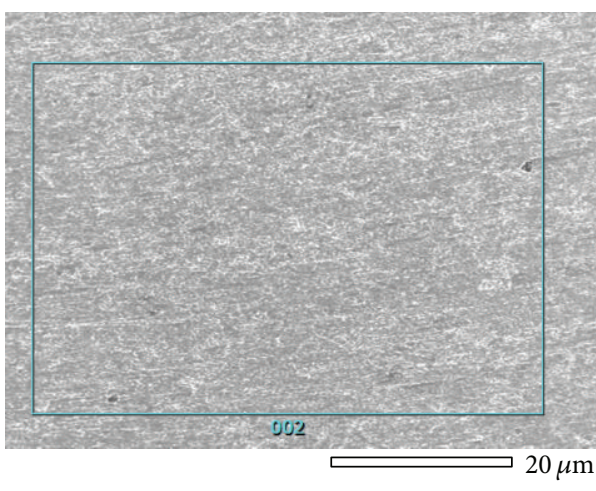

(a)

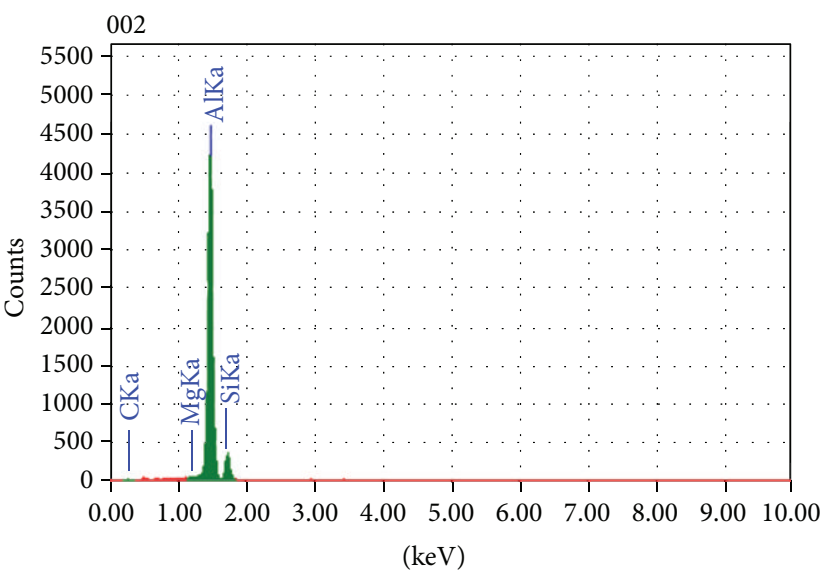

(b)

FIGURE 14: (a) Surface of the Al-7.5 wt.\% Gr composite before wear testing. (b) EDS spectrum of MML of the Al-7.5 wt.\% Gr composite before wear testing.

Worn surface of Al-7.5 wt.\% Gr composite contains larger amount of oxides when increasing the sliding speed from $1 \mathrm{~m} / \mathrm{s}$ to $2 \mathrm{~m} / \mathrm{s}$ at $49 \mathrm{~N}$ as demonstrated in Figure 16 . It can be observed that about $40 \%$ (by mass) of oxide element was recorded on the worn surface at $2 \mathrm{~m} / \mathrm{s}$ and $49 \mathrm{~N}$. This indicates that the oxidation wear mechanism is predominant under higher sliding speed. The existence of more $\mathrm{O}$ infers that $\mathrm{Al}$, graphite, and $\mathrm{Fe}$ could have been oxidized during sliding since the wear process is exposed to the air. It could be the reason that the higher sliding velocity generates more frictional heat at the interface between the two sliding elements and accelerates the oxidation process. As a result, oxide layer is formed on the worn surface which enhances the wear resistance of the composites. In addition, EDS test infers that the some amount of iron has also been transferred from the counter steel disc to the composite pin during wear process. This layer is called mechanically mixed layer (MML) which contains a mixture of materials from both the contact surfaces such as $\mathrm{Fe}$ oxide, graphite, and $\mathrm{Al}$ oxide. This observation confirms that at higher sliding velocities, the oxide fragments spread on the worn surface and get better compacted to form tribolayer and then act as solid lubricating film which enhances the wear resistance. 


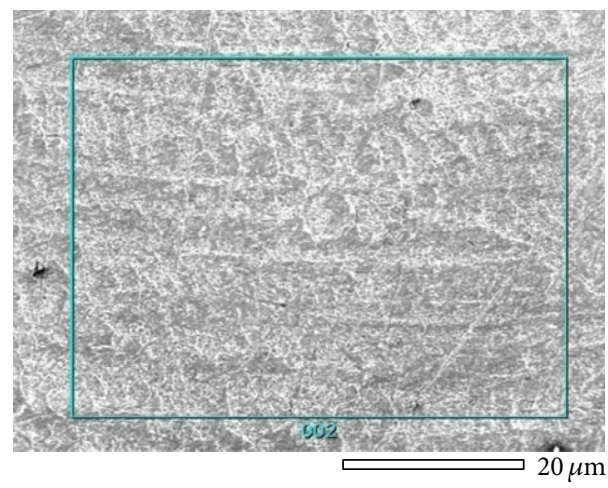

(a)

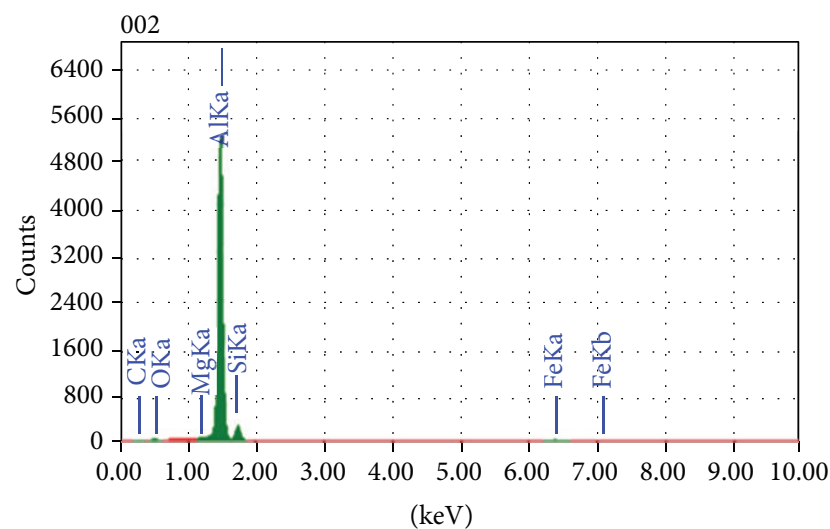

(b)

FIGURE 15: (a) MML on the worn surface of the Al-7.5 wt.\% Gr composite. (b) EDS spectrum of MML of the Al-7.5 wt.\% Gr composite when tested at $49 \mathrm{~N}, 2 \mathrm{~m} / \mathrm{s}$.

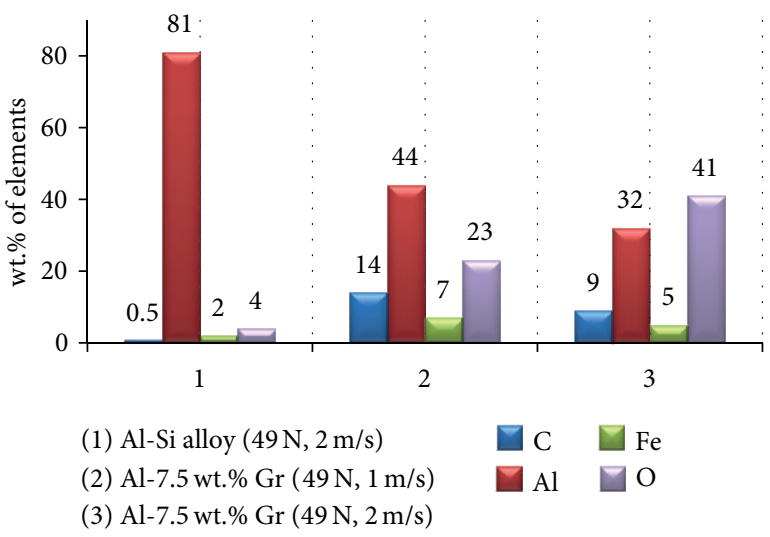

Figure 16: Mass percentage of $\mathrm{Al}, \mathrm{Fe}, \mathrm{C}$ and oxides as a function of sliding velocities on the worn surface of the Al alloy and Al-7.5 wt.\% Gr composite against the counter steel obtained by EDS.

\section{Conclusions}

Al-Si alloy-graphite composites were successfully fabricated by employing both modified two-stage stir casting and squeeze casting methods. Al-Gr composites have shown lower hardness compared to the $\mathrm{Al}$ alloy. Hardness of composites linearly decreases with increasing the weight percentage of graphite particles. Wear and friction coefficients of Al-Gr composites tend to decrease with increasing the graphite content due to the formation of graphite film on the surface. It was observed that the dry sliding wear resistance of the Al-7.5 wt.\% graphite is about 2.2 times higher than that for the base alloy and keeps the best wear resistance. EDS test confirmed that the wear resistance of the Al-Gr composites increased with increasing sliding velocity by sustaining the stable tribolayer on the surface of the composites. On the other hand, the friction coefficient of Al7.5 wt. $\%$. Gr composite increased by $10 \%$ when sliding velocity was increased from $1 \mathrm{~m} / \mathrm{s}$ to $2 \mathrm{~m} / \mathrm{s}$ at constant applied load of $49 \mathrm{~N}$. It should be noted that the appropriate quantity of the graphite content can be added to the Al alloy to enhance the tribological properties of composites without compromising too much of its mechanical properties.

\section{Acknowledgment}

The authors are grateful to the Faculty of Engineering, Department of Automobile Engineering, Karpagam University, Coimbatore, for providing the facilities to carry out this project successfully.

\section{References}

[1] B. Bhushan, "Tribology: friction, wear, and lubrication," in The Engineering Handbook, R. C. Dorf, Ed., CRC Press LLC, Boca Raton, Fla, USA, 2000.

[2] C. B. Lin, R. J. Chang, and W. P. Weng, "A study on process and tribological behavior of $\mathrm{Al}$ alloy/Gr.(p) composite," Wear, vol. 217, no. 2, pp. 167-174, 1998.

[3] W. Ames and A. T. Alpas, "Wear mechanisms in hybrid composites of Graphite-20 Pct SiC in A356 Aluminum Alloy (Al-7 Pct Si-0.3 Pct Mg)," Metallurgical and Materials Transactions A, vol. 26, no. 1, pp. 85-98, 1995.

[4] S. Das, S. V. Prasad, and T. R. Ramachandran, "Microstructure and wear of cast (Al-Si alloy)-graphite composites," Wear, vol. 133, no. 1, pp. 173-187, 1989.

[5] Y. B. Liu, S. C. Lim, S. Ray, and P. K. Rohatgi, "Friction and wear of aluminium-graphite composites: the smearing process of graphite during sliding," Wear, vol. 159, no. 2, pp. 201-205, 1992.

[6] J. Leng, L. Jiang, G. Wu, S. Tian, and G. Chen, "Effect of graphite particle reinforcement on dry sliding wear of $\mathrm{SiC} / \mathrm{Gr} / \mathrm{Al}$ composites," Rare Metal Materials and Engineering, vol. 38, no. 11, pp. 1894-1898, 2009.

[7] P. R. Gibson, A. J. Clegg, and A. A. Das, "Wear of cast Al-Si alloys containing graphite," Wear, vol. 95, no. 2, pp. 193-198, 1984.

[8] B. C. Pai, P. K. Rohatgi, and S. Venkatesh, "Wear resistance of cast graphitic aluminium alloys," Wear, vol. 30, no. 1, pp. 117125, 1974.

[9] B. P. Krishnan, N. Raman, K. Narayanaswamy, and P. K. Rohatgi, "Performance of aluminum alloy graphite bearings in a diesel engine," Tribology International, vol. 16, no. 5, pp. 239-244, 1983.

[10] N. Barekar, S. Tzamtzis, B. K. Dhindaw, J. Patel, N. Hari Babu, and Z. Fan, "Processing of aluminum-graphite particulate metal matrix composites by advanced shear technology," Journal of 
Materials Engineering and Performance, vol. 18, no. 9, pp. 12301240, 2009.

[11] P. Shanmughasundaram, R. Subramanian, and A. R. Ravikumar, "Analysis of dry sliding wear behaviour of aluminium-fly ash composites: the Taguchi approach," Advances in Mechanical Engineering, vol. 2013, Article ID 658085, 10 pages, 2013.

[12] P. Shanmughasundaram, R. Subramanian, and G. Prabhu, "Synthesis of Al-fly ash composites by modified two step stir casting method," Advanced Materials Research, vol. 488-489, pp. 775-781, 2012.

[13] A. M. Hassan, G. M. Tashtoush, and J. A. Al-Khalil, "Effect of graphite and/or silicon carbide particles addition on the hardness and surface roughness of Al- $4 \mathrm{wt} \% \mathrm{Mg}$ alloy," Journal of Composite Materials, vol. 41, no. 4, pp. 453-465, 2007.

[14] M. R. Rosenberger, C. E. Schvezov, and E. Forlerer, "Wear of different aluminum matrix composites under conditions that generate a mechanically mixed layer," Wear, vol. 259, no. 1-6, pp. 590-601, 2005. 

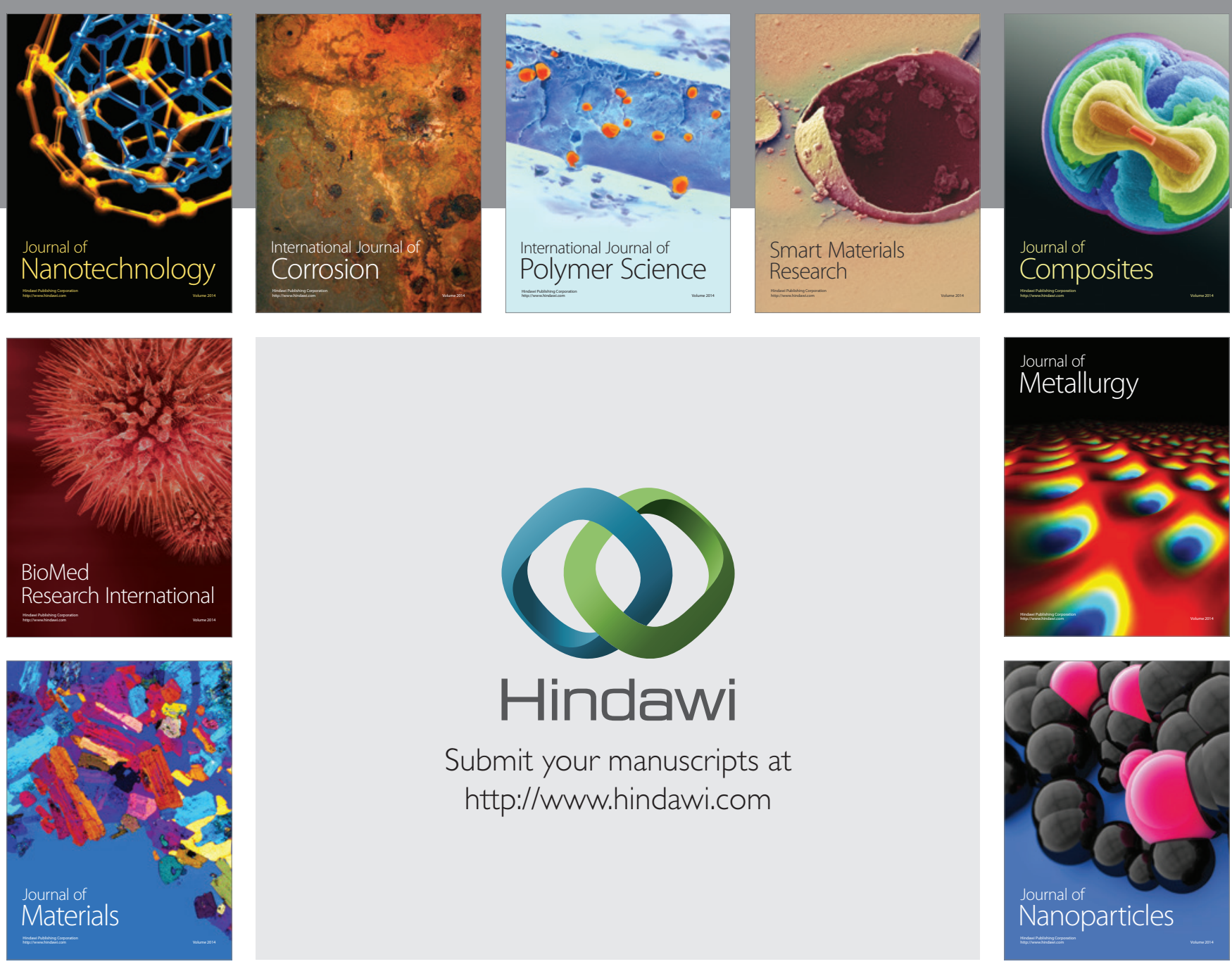

Submit your manuscripts at http://www.hindawi.com
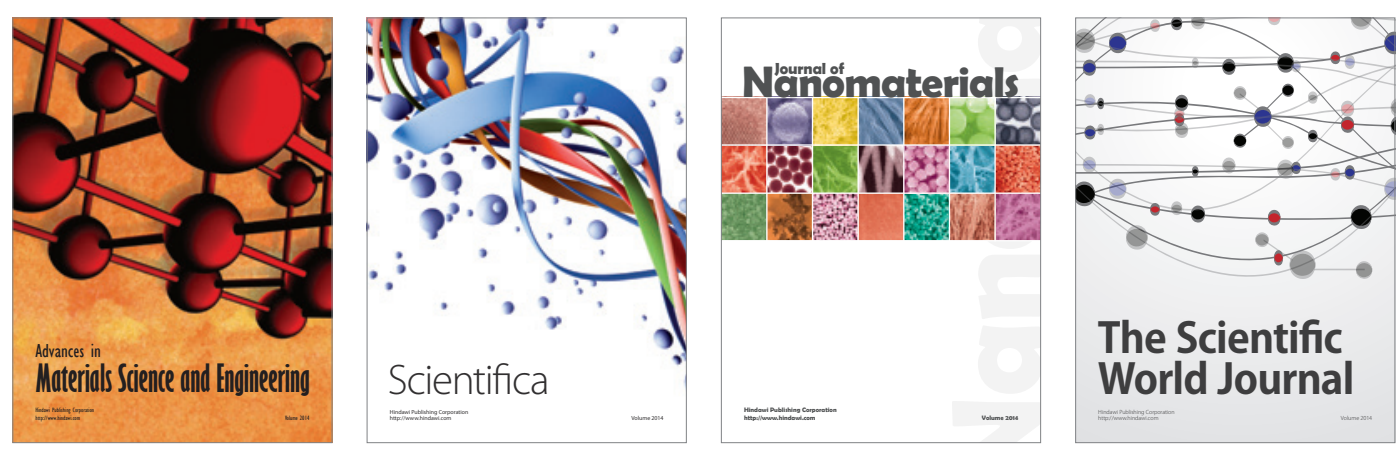

\section{The Scientific World Journal}
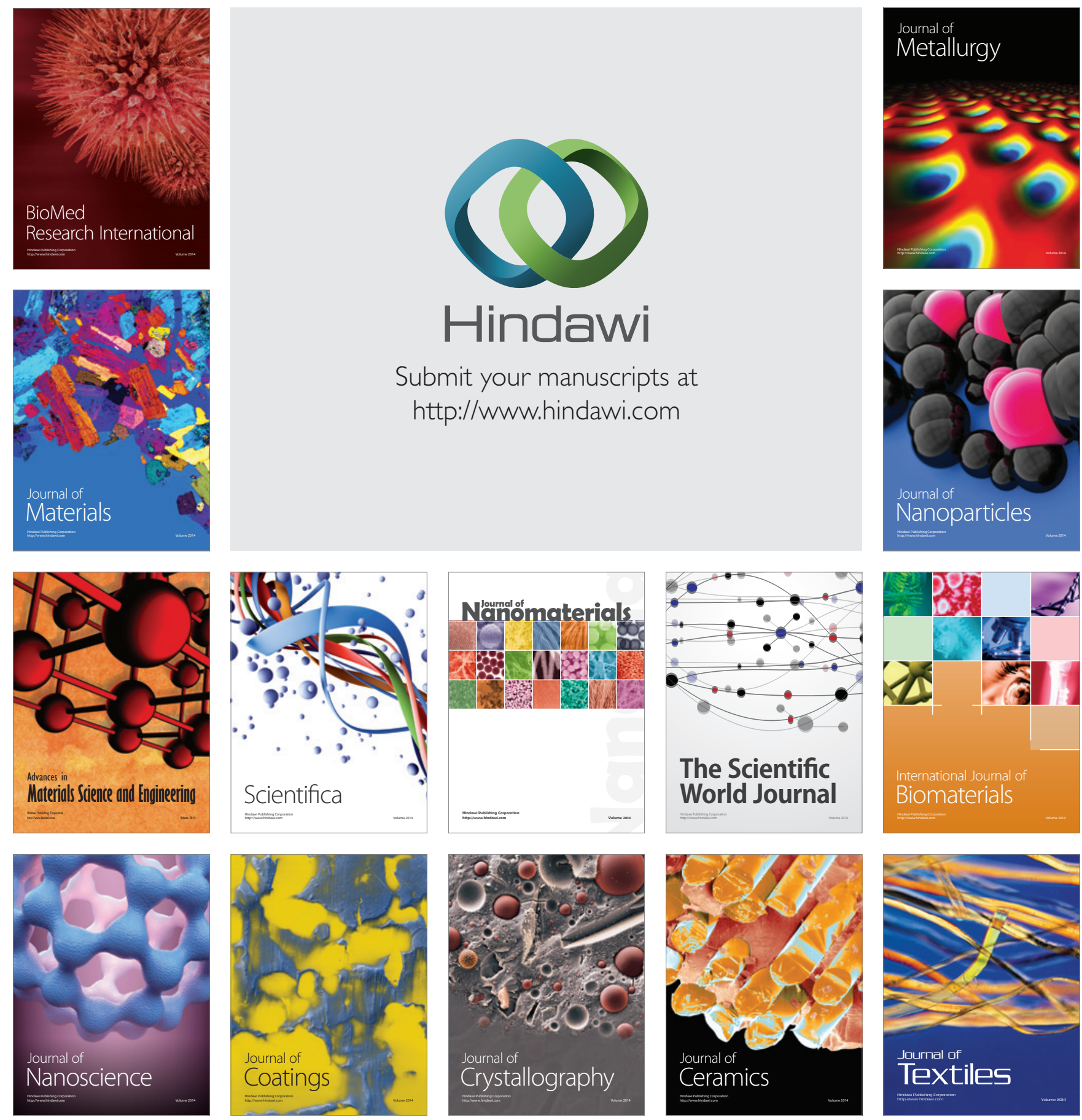